\title{
Study of coupling photocatalysis and membrane separation using tubular ceramic membrane made from natural Moroccan clay and phosphate
}

\author{
Noureddine El Baraka ${ }^{1}$, Abdellatif Laknifli $^{2}$, Nabil Saffaj ${ }^{3}$, Mourad $_{\text {Addich }}{ }^{2}$, Abdelaziz. Ait Taleb $^{1}$, Rachid. Mamouni ${ }^{2}$, \\ Abdelilah Fatni ${ }^{1}$ and Mohamed. Ait Baih ${ }^{3}$ \\ ${ }^{1}$ Laboratory of Biotechnology, Materials and Environment, Physicochemistry of Natural Environments, Materials and Environment \\ Team, Faculty polydisciplinaire, University Ibn Zohr, BP 271, Taroudant, Morocco \\ ${ }^{2}$ Laboratory of Biotechnology, Materials and Environmen. Physicochemistry of Natural Environments, Materials and Environment \\ Team, Faculty of Sciences, University Ibn Zohr, BP 8106, Cite Dakhla, Agadir, Morocco \\ ${ }^{3}$ Laboratory of Biotechnology, Materials and Environment. Physicochemistry of Natural Environments, Materials and Environment \\ Team, Faculty polydisciplinaire,University Ibn Zohr, BP 638, Ouarzazate, Morocco
}

\begin{abstract}
This paper is devoted to study the feasibility of combining photocatalytic degradation with membrane filtration for the removal of organic pollutants. As a result, we have successfully prepared lowcost microfiltration membranes based on clay and phosphate. It is expected that the phosphate and clay composite membrane can have multifunctional separation and photocatalysis simultaneously and this type of composite membrane can play an important role in the photocatalytic reaction in presence of $\mathrm{TiO} 2$ and the separation process. We then tested the efficiency of the direct coupling of photodegradation and filtration to determine the rate of release of $\mathrm{TiO}_{2}$ particles through the microfiltration membrane. However, we have seen that the recovery of $\mathrm{TiO}_{2}$ exceeds a $96 \%$, as well as the removal of products from the photodecomposition of the reaction mixture in the membrane photocatalytic reactor. In our case the methylene blue elimination rate exceeds $75 \%$.
\end{abstract}

\section{Introduction}

Nowadays water pollution, caused by hazardous organic chemicals used in industry and agriculture, is a very serious problem. Food, pharmaceutical, pesticides, the textile dyeing and finishing industry produces large volumes of discharge effluent and is considered as one of the major industrial pollutants.

Compared with conventional water treatments, which operate in discontinuous and produce large quantities of sludge which are disposed in land fill, the membrane processes are used to purify water continuously, without chemical additives. Therefore microfiltration (MF) separation is widely used as a solid-liquid separation technique in the drink and food industries and in biotechnology.

The microfiltration membrane we made from natural Moroccan clay [1-3] and phosphate [4] show their potentialities in the rationalization of productions systems. Their intrinsic characteristics of efficiency, operational simplicity and flexibility, relatively high selectivity and permeability for the transport of specific components, low energy requirements, good stability under a wide spectrum of operating conditions, easy control and scale up have been confirmed in a large variety of application, and operations.
Till now, heterogeneous photocatalysis has been mainly applied for environmental remediation because the photogenerated active species are capable to mineralize efficiently almost every organic pollutant. In general, photocatalysis can be defined as an acceleration of a photoinduced reaction by the presence of a photocatalyst [5]. Also that, Photocatalysis is one of the so-called "Advanced Oxidation Processes" (AOPs). AOPs are based on the generation of very reactive specieshydroxyl radicals $(\mathrm{OH} \bullet)$ that could oxidize wide spectra of organic matter in water quickly and non-selectively [6]. Although, the presence of these compounds in the environment corresponds to low concentration levels, its continuous input from wastewater treatment plants or direct discharge to natural riverbeds may represent a long-term potential threat for the aquatic and terrestrial ecosystems. A coupling system of membrane separation and photocatalytic oxidation has been evaluated for the removal of organic pollutants in wastewaters [7]. Coupling photocatalysis and membrane separation can be use three main configurations can be distinguished: (a) irradiation of the feed tank, (b) irradiation of the membrane module or (c) irradiation of an additional reservoir (photoreactor) which is located between the feed tank and the membrane module Figs 1-3 [6]. In some cases the light source can be positioned above 
both, membrane module and feed tank (or inside them, when the immersed UV lamps are used).

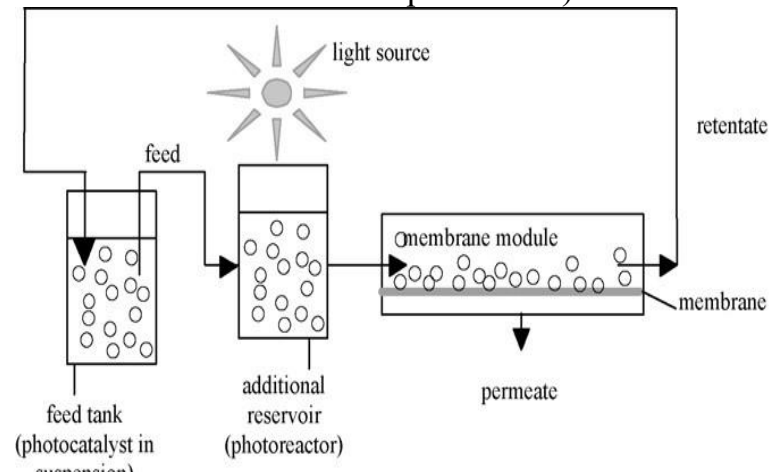

Fig. 1. Hybrid photocatalysis-membrane processes utilizing irradiation of the additional reservoir located between the feed tank and membrane module.

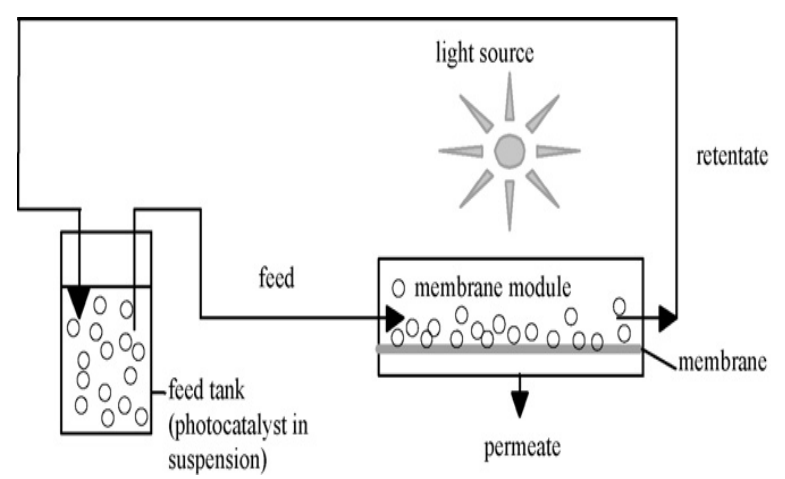

Fig. 2. Hybrid photocatalysis-membrane processes utilizing irradiation of the membrane module.

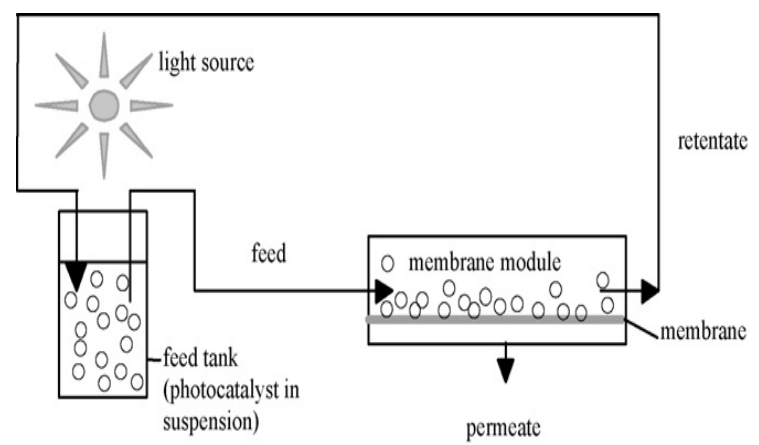

Fig. 3. Hybrid photocatalysis-membrane processes utilizing irradiation of the feed tank.

The aim of this work is to understand this behavior and to improve the performance of coupling photocatalysis and membrane separation, in order to take advantage of the benefits of both the photocatalytic and membrane technology for water treatment. The aqueous solution containing methylene blue is fed to the membrane unit, obtaining a permeate free of pollutants and a rejected flux with high concentration. Subsequently, the rejected stream was treated by photocatalytic system of them using $\mathrm{TiO}_{2}$ as heterogeneous catalyst.

A comparative study between the photocatalytic coupling-clay microfiltration membrane and the photocatalytic coupling-phosphate microfiltration membrane for the removal of methylene blue using the configuration shown in Fig.3.

\section{The use of methylene blue (MB) in photocatalytic-membrane coupling}

Most of industries like textiles, paper, plastics, leather, food, and cosmetics industries use dyes or pigments to color their product. It can cause eye burns causing permanent injury to human and animal eyes. Inhalation may cause respiration difficulties and oral ingestion may cause burning, nausea, vomiting, sweating and heavy cold sweats [8]. The treatment of industrial discharges containing this type of dye is of great interest [9-10]. Indeed, the validation study of this new method will be based on this dye (MB) which is a cationic dye with broad applications such as dye for paper, hair, and cotton and filters for medical surgery [11]. This pollutant not only deteriorates water quality but also significantly affects the environment and human health [12], this is why this dye is chosen as a representative model of medium-sized organic pollutants.

The aim of this work is to understand this behavior and to improve the performance of coupling photocatalysis and membrane separation, in order to take advantage of the benefits of both the photocatalytic and membrane technology for water treatment. The aqueous solution containing methylene blue is fed to the membrane unit, obtaining a permeate free of pollutants and a rejected flux with high concentration. Subsequently, the rejected stream was treated by photocatalytic system of them using $\mathrm{TiO}_{2}$ as heterogeneous catalyst.

\section{Materials and methods}

\subsection{Materials}

Methylene blue is a cationic dye of index C. I 52015, formula $\mathrm{Cl}_{6} \mathrm{H}_{18} \mathrm{~N}_{3} \mathrm{SCl}$ and its molar mass is $319.85 \mathrm{~g}$. mol-1. Its visible spectrum is shown in Figure 4 [13].

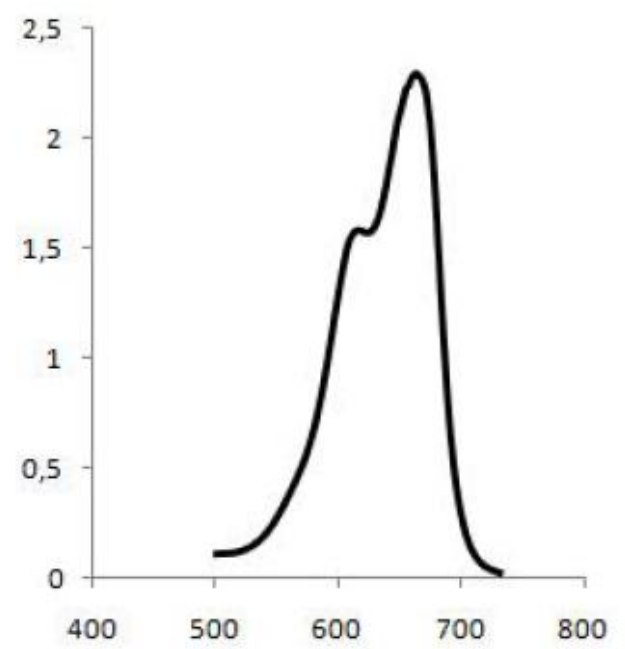

Fig. 4. Visible spectrum of the methylene blue dye studied.

The semi-developed formula of this dye is shown in Fig.5. 
<smiles>CN(C)c1ccc2nc3ccc(N(C)C)cc3[s+]c2c1</smiles>

Fig. 5. Molecular Structures of Methylene Blue.

The raw clay used in this work is clay taken from a natural basin in the region of Souss (Morocco), crushed and sieved to obtain fractions $\leq 125 \mu \mathrm{m}$ and then dried at $100{ }^{\circ} \mathrm{C}$ for $24 \mathrm{~h}$.

Natural Moroccan phosphates from Khouribga was used to prepare lixiviated phosphate, the powder was crushed and sieved to obtain fractions $\leq 125 \mu \mathrm{m}$ with disc mills Mc call [4].

Chemical analyses of raw Moroccan clay and phosphate were carried out using the X-ray fluorescence spectrometer, the results are grouped in Table 1.

Table 1: Mineralogical composition of clay and phosphate.

\begin{tabular}{ccc}
\hline & Clay sample & $\begin{array}{l}\text { Phosphate } \\
\text { sample }\end{array}$ \\
\hline Element & Weight \% & Weight \% \\
\hline $\mathrm{Al}_{2} \mathrm{O}_{3}$ & 43 & 0.29 \\
$\mathrm{SiO}_{2}$ & 35 & 1.4 \\
$\mathrm{Fe}_{2} \mathrm{O}_{3}$ & 15 & 0.12 \\
$\mathrm{Na}_{2} \mathrm{O}$ & 3.5 & 1.1 \\
$\mathrm{CaO}$ & 1.5 & 51.59 \\
$\mathrm{~K} 2 \mathrm{O}$ & 1.2 & 0.06 \\
$\mathrm{MnO}$ & 0.03 & - \\
$\mathrm{P}_{2} \mathrm{O}_{5}$ & - & 33.4 \\
$\mathrm{SO}_{3}$ & - & 1.56 \\
$\mathrm{CO}_{2}$ & - & 4.39 \\
$\mathrm{MgO}$ & - & 0.25 \\
$\mathrm{~F}-$ & - & 4.08 \\
\hline
\end{tabular}

Anatase-type titania have been proven as environmental friendly catalysts because of its capability to decompose the different organic and inorganic pollutants [14]. However, the best photocatalytic performances with maximum quantum yields have been always obtained with titania [15]. In addition, anatase is the most active allotropic form of $\mathrm{TiO} 2$ among the various ones available [16]. Unfortunately, due to a wide band gap (about $3.2 \mathrm{eV}$ ) $\mathrm{TiO} 2$ is inactive under visible light [17]. Recently, numerous investigations have been focused on different modifications of $\mathrm{TiO} 2$ in order to improve its activity under UV irradiation or to reduce the band gap energy so that it is able to utilize the visible light [1820]. An overview of various modification techniques which could improve $\mathrm{TiO} 2$ activity under visible light was recently presented by Rehman et al. [17].

\subsection{Methods}

\subsubsection{Water permeability test}

Before using the elaborated ceramic membranes, it is necessary to make a test to determine the permeability to distilled water. The agitated reactor is pre-filled with distilled water, then a valve was used to control the pressure in the system, it varies between 0 and 2 bar, the valve is opened which makes it possible to send the water with the aid of a pump to the microfiltration reactor Fig.6. Membranes were conditioned by immersion in pure deionised water for a minimum of 24 $\mathrm{h}$ before the filtration tests.

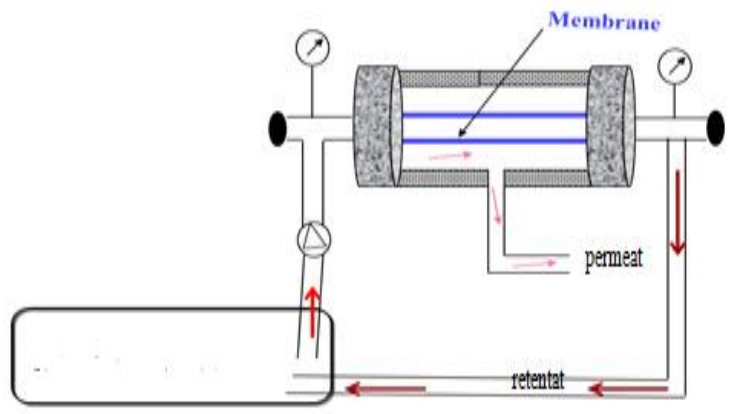

Fig. 6. Scheme of the pilot of filtration.

\subsubsection{Methylene blue filtration on $\mathrm{ZrO}_{2} /$ phosphate and $\mathrm{ZrO}_{2} /$ clay}

We performed a BM filtration at an initial concentration of $25 \mathrm{ppm}$ on a tubular membrane of $\mathrm{ZrO} 2$ deposited on a phosphate support [4], the experiment was done in absence of $\mathrm{TiO} 2$ and at a pressure of 1 bar. We have thus realized the same study and the same condition, but this time on a tubular clay microfiltration membrane.

Next, we carried out a filtration in the presence of $\mathrm{TiO}_{2}$ through the membrane of $\mathrm{ZrO}_{2} /$ Phosphate under the same conditions of BM concentration and pressure and without irradiation.

\subsubsection{Study of BM adsorption on TiO2 in darkness}

The adsorption of dyes on the surface of semiconductors is an important process. Indeed, the adsorption of the micro pollutant on the photocatalyst is a step prior to its degradation, very important for the development of the photodegradation reaction. It should be noted, however, that this process is debated. According to some authors [7-9], adsorption is a prerequisite for photodegradation.

The adsorption capacity of the methylene blue dye per unit mass of $\mathrm{TiO} 2$ has been calculated using the following formula:

$$
q=\left[\left(C_{0^{-}} C_{t}\right] x \mathrm{~V} / \mathrm{mTiO} \mathrm{O}_{2}\right.
$$

Were $\mathrm{q}$ is the quantity of $\mathrm{BM}$ adsorbed at time $\mathrm{t}, \mathrm{m}$ the mass of $\mathrm{TiO}_{2}(\mathrm{mg} / \mathrm{g} \mathrm{TiO} 2), \mathrm{C} 0$ the initial concentration of BM (mg. $\left.\mathrm{L}^{-1}\right)$ and $\mathrm{Ct}$ the concentration of BM at time $\mathrm{t}$ 


\section{a. . Determination of adsorption equilibrium time}

All adsorption isotherms were performed in the dark after a $60 \mathrm{~min}$ equilibrium period at natural $\mathrm{pH}$ and $25^{\circ} \mathrm{C}$. The same amount of $\mathrm{TiO}_{2}$ adsorbent (1 g.L-1) Various aqueous dye solutions were added to $100 \mathrm{~mL}$ at concentrations $20,40,60,80$ and $100 \mathrm{mg} . \mathrm{L}-1$ before being mechanically agitated at $200 \mathrm{rpm}$ at room temperature.

\section{b. Effect of temperature}

The influence of temperature was studied using a thermostat bath to maintain temperature at desired value $\left(25^{\circ}, 30^{\circ}, 35^{\circ}\right.$, and $\left.40^{\circ} \mathrm{C}\right)$. The experiments were achieved by adding $12 \mathrm{mg} / \mathrm{L}$ of methylene blue solution.

\section{c. Effect of $\mathrm{pH}$}

The influence of the $\mathrm{pH}$ of the solution on adsorption was studied using different $\mathrm{pH}$ values. The experiments were carried out by adding $0.2 \mathrm{~g} / \mathrm{L}$ of $\mathrm{TiO} 2$ to the Methylene blue $\left(\mathrm{T}=25^{\circ} \mathrm{C}, \mathrm{C} 0=10 \mathrm{ppm}\right)$.

\section{d. Effect of $\mathrm{TiO}_{2}$ doses}

The study of the effect of increasing the quantity of semiconductor on the adsorption of dyes, for the BM dye, within a series of concentrations of the catalyst (TiO2) stretching from $0.5 \mathrm{~g} / \mathrm{L}$ to $3 \mathrm{~g} / \mathrm{L}$ and a dye concentration of $20 \mathrm{ppm}$.

\subsubsection{Removal of MB from the membrane- photocatalytic reactor}

After testing the reactor for distilled water and testing the adsorption of MB under different conditions, we performed photocatalytic degradation experiments (UV lamp $30 \mathrm{~W}$ ) followed directly by tangential filtration of methylene blue.

The feed reactor is pre-filled with the MB solution at a concentration of $25 \mathrm{mg} / \mathrm{L}$, before adding the $\mathrm{TiO} 2$ semiconductor of $1 \mathrm{~g} / \mathrm{L}$ of the catalyst used in powder form. it is left stirring for 10 minutes, then the valve is opened which allows to send the reaction mixture before the photocatalytic degradation to the photochemical reactor to the microfiltration reactor, by means of a pump. the stirring speed is set, the recirculation flow rate of the reaction mixture depends on the applied pressure. samples are taken every 10 minutes. In $\mathrm{BM}$ photodegradation reactions, the $\mathrm{pH}$ of the suspension is about 6.5 the initial volume of the reaction mixture is $2 \mathrm{~L}$.

\section{Results and discussion}

\subsection{Study of $\mathrm{MB}$ adsorption on $\mathrm{TiO}_{2}$.}

\subsubsection{Time of equilibrium adsorption}

Figure 7 shows that the increase in the initial BM concentration leads to a substantial increase in the amount of BM selected for the same amount of $\mathrm{TiO} 2$. The amount of adsorbed BM becomes constant for an equilibrium time of $40 \mathrm{~min}$ and an initial concentration above $\mathrm{C} 0=60 \mathrm{ppm}$ of $\mathrm{BM}$.

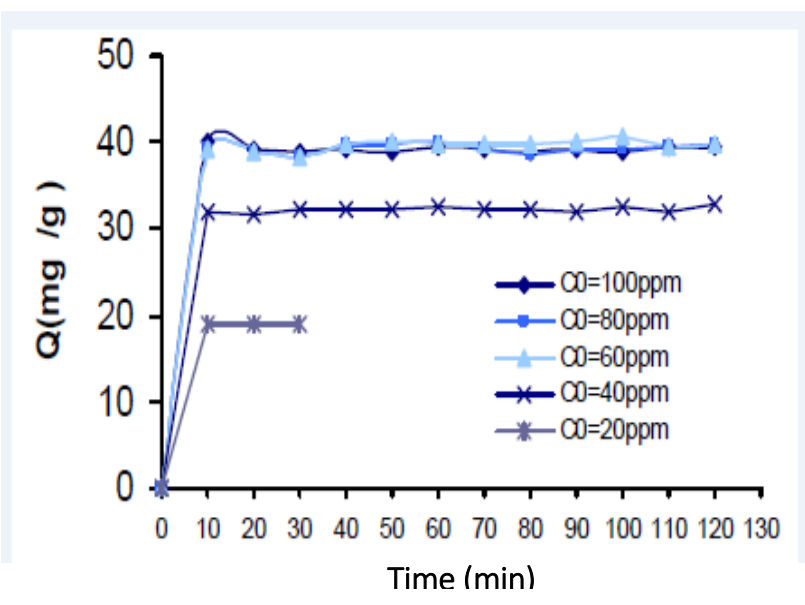

Fig. 7. Effect of initial $\mathrm{BM}$ concentration on $\mathrm{TiO} 2$ adsorption kinetics.

\subsubsection{Influence of temperature on adsorption}

In the range temperature considered, the temperature does not have a large effect on adsorption. A small increase in adsorbed amounts is observed with the increase in temperature (Fig.8).

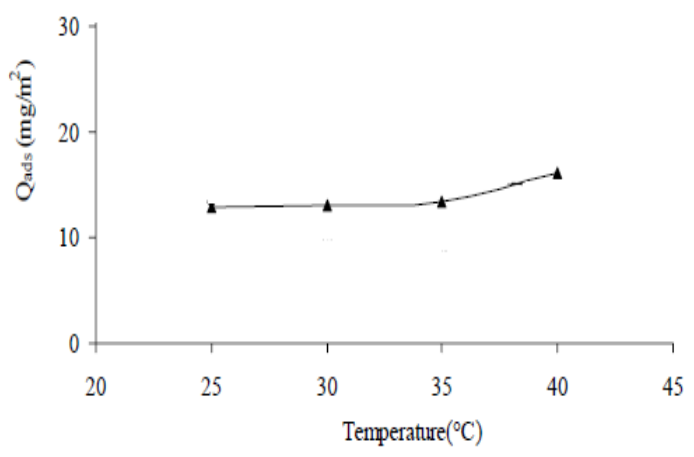

Fig. 8. Effect of temperature on the adsorbed amount of $\mathrm{BM}$ on the photocatalyst.

Increasing the temperature would increase the mobility of ionized dye molecules, and would result in a widening of the pores in the internal structure of the adsorbent. This would allow dye molecules to penetrate.

\subsubsection{Influence of $\mathrm{pH}$}

The curve in Figure 9 shows that the $\mathrm{pH}$ parameter improves the removal percentage, when the $\mathrm{pH}$ increases from 4 to 7 the percentage of elimination increases from $34 \%$ to $91 \%$ and when the $\mathrm{pH}$ changes from 7 to 14 a decrease from $91 \%$ to $77 \%$. The maximum percentage 
of elimination is $91 \%$ which corresponds to the zero load point (ZLP) for $\mathrm{TiO} 2$ particles at $\mathrm{pH}=6.8$.

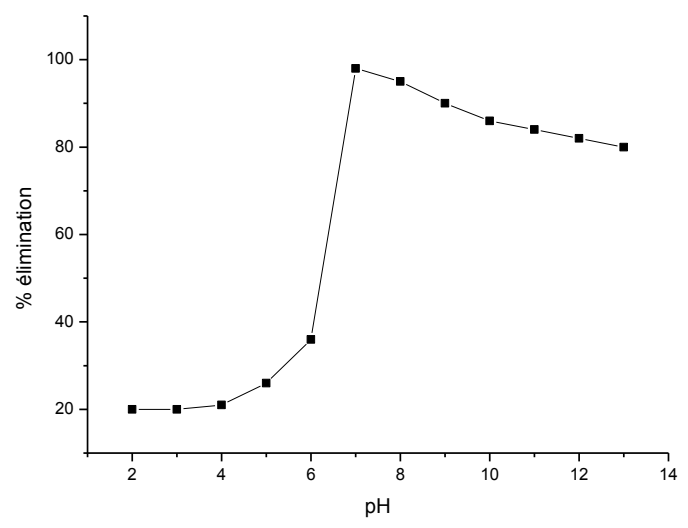

Fig. 9. Effect of $\mathrm{pH}$ on $\mathrm{BM}$ equilibrium adsorption rate in darkness

\subsubsection{Influence of TiO2 concentration on adsorption rate}

The results of the evolution of the adsorbed amount of dye over contact time are shown in Figure 10 and show that the increase in the concentration of catalysts $\left(\mathrm{TiO}_{2}\right)$ causes an increase in the adsorption rate.

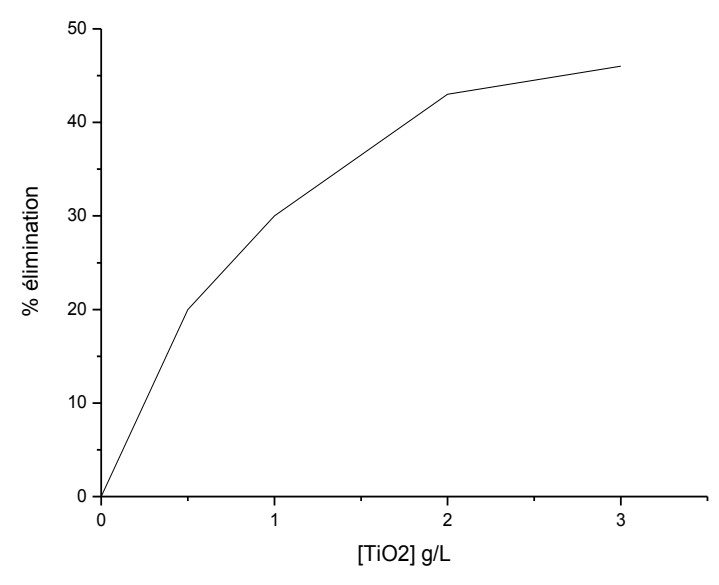

Fig. 10. Evolution of the adsorbed amount of the dye as a function of the concentration of $\mathrm{TiO}_{2}$ in the dark.

\subsection{Study of $\mathrm{BM}$ removal by $\mathrm{TiO}_{2}$ photocatalysis}

\subsubsection{Effect of initial concentration}

Before any study, photolysis alone of methylene blue under solar irradiation was carried out in aqueous solution. It was found to be negligible, since only $2 \%$ discolouration of the dye is observed in 90 min. Moreover, Figure 11 shows that, when irradiating the solution with a concentration of $\mathrm{TiO} 2$ of $0,2 \mathrm{~g} / \mathrm{L}$, the dye is completely eliminated for low concentrations.

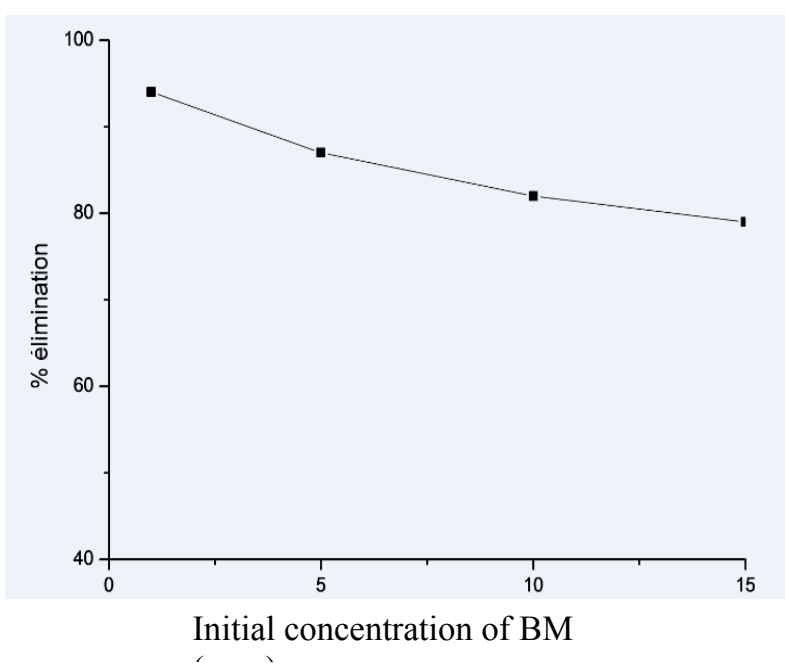

Fig. 11. Effect of initial concentration on BM removal.

Logically, the effectiveness of discolouration decreases with the increase of the dye concentration. Some justifications of this behaviour can be considered. First, it is possible that the photogeneration of $\mathrm{h}+$ holes and/or $\mathrm{OH}^{\circ}$ radicals on the catalyst surface may be reduced due to the covering of the active sites by the dye. Another justification would be that the absorption of a significant amount of UV by dye molecules rather than by the surface of $\mathrm{TiO} 2$ reduces the intensity of the absorbed radiation at the catalyst, thus reducing the efficiency of the photocatalytic reaction.

\subsubsection{Influence of $\mathrm{pH}$ on photocatalysis}

Since the $\mathrm{pH}$ of the dye solution is an essential parameter for the progression of degradation, comparative experiments were carried out at different $\mathrm{pH}$ values: an acidic $\mathrm{pH}(3.3)$, two of the basic $\mathrm{pH}(11.4 ; 13.3)$ and a natural $\mathrm{pH}$ (7.7). Figure 12 illustrates the variation in the amount of dye removed as a function of the $\mathrm{pH}$ of the solution at a fixed temperature.

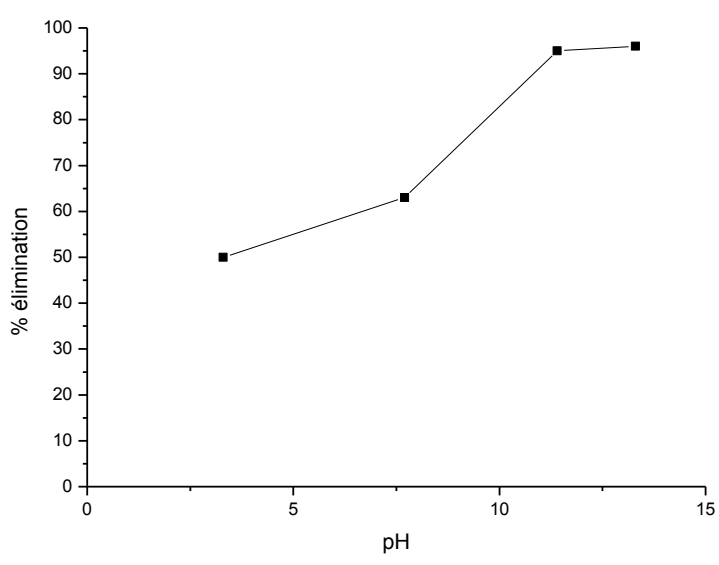

Fig. 12. Effect of $\mathrm{pH}$ on $\mathrm{BM}$ removal.

4.3 Study of BM removal on the microfiltration membrane

4.3.1 Test of permeability 
Fig. 13 shows that the water flux through the membrane depends on the applied pressure but the stabilization of the flux needs about 0.5 hour due to formation of a polarization layer. The permeability was determined from the values of flux measured after stabilisation for each working pressure. The curve given the flux vs. pressure is a straight line with slop equal to about 121.6 L/h.m ${ }^{2}$.bar which corresponds to the permeability of the membrane (Fig. 14).

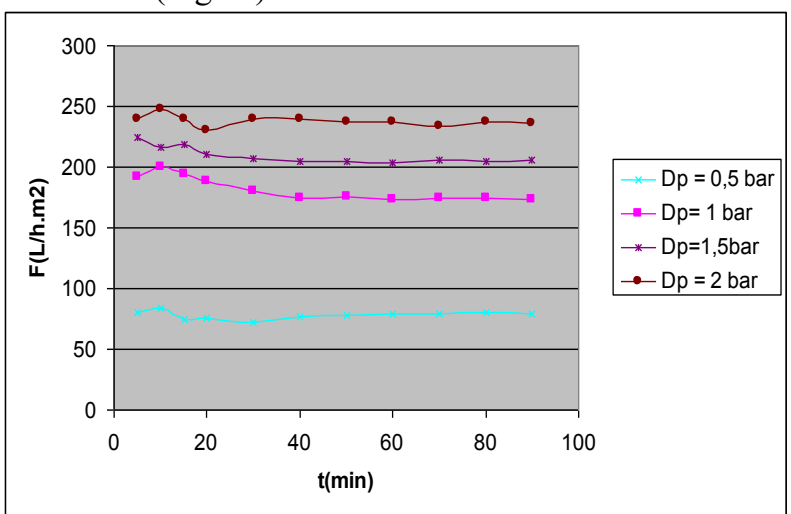

Fig. 13. Evolution of water permeation flux as a function of time.

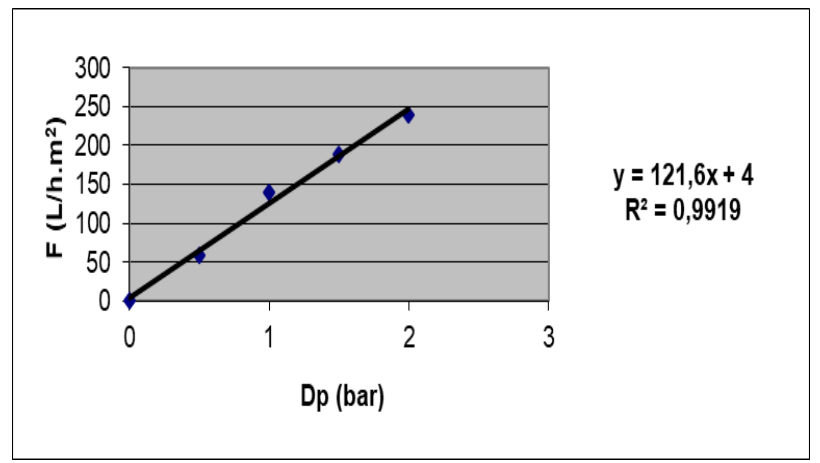

Fig. 14. Evolution of water permeation flux as a function of pressure.

\subsubsection{Filtration of $B M$ on membrane ZrO2/phosphate and ZrO2/Clay}

- Filtration on $\mathrm{ZrO} 2 /$ phosphate: The results presented in Figure 15 show that the release rate reaches a maximum value of $3.5 \%$ after 40 minutes of filtration. This confirms that the BM is not well retained by a microfiltration membrane.

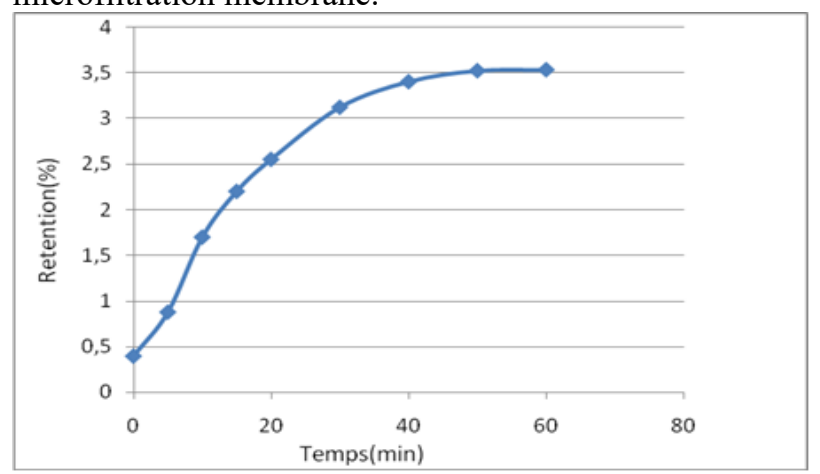

Fig. 15. Filtration of $\mathrm{BM}$ without $\mathrm{TiO} 2$ and without irradiation on $\mathrm{ZrO} 2 / \mathrm{Phosphate}$
Next, we carried out a filtration in the presence of $\mathrm{TiO}_{2}$ through the membrane of $\mathrm{ZrO}_{2} /$ Phosphate under the same conditions of $\mathrm{BM}$ concentration and pressure in the presence of $\mathrm{TiO} 2$. Figure 16 showed that the rejection rate improved by comparing it with the previous figure. This can be explained by an adsorption of $\mathrm{BM}$ on $\mathrm{TiO}_{2}$.

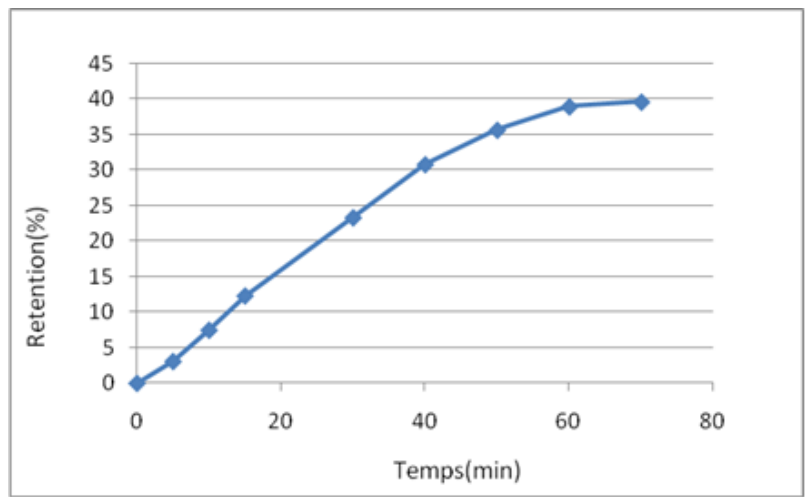

Fig. 16. Filtration of $\mathrm{BM}$ in the presence of $\mathrm{TiO} 2$ and without irradiation on $\mathrm{ZrO} 2 / \mathrm{Phosphate}$.

- Filtration on $\mathrm{ZrO} 2 /$ clay : We carried out the same study but this time with microfiltration membrane based on clay.

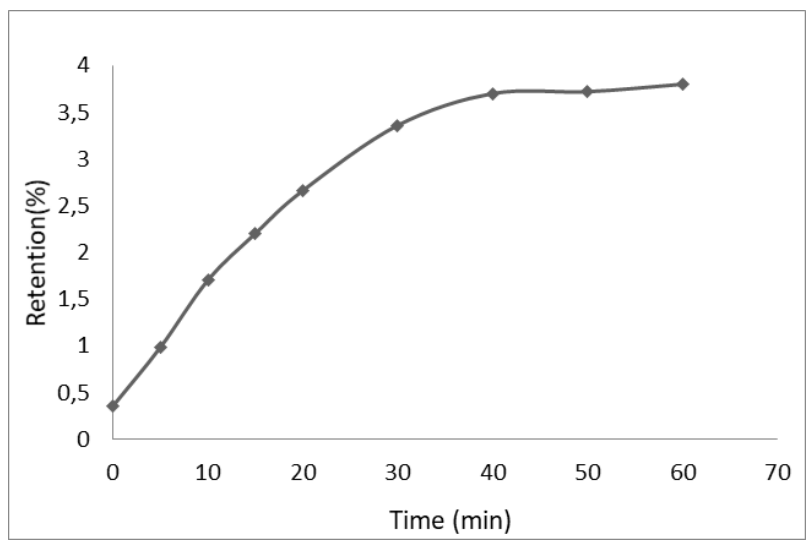

Fig. 17. Filtration of $\mathrm{BM}$ without $\mathrm{TiO} 2$ and without irradiation on $\mathrm{ZrO} 2 /$ Clay.

After a filtration test on a microfiltration membrane, we found that the release rate (Figure 17) reaches a maximum value of $3,8 \%$ after $40 \mathrm{~min}$. This confirms that the $\mathrm{BM}$ is not well retained by a microfiltration membrane. The results presented in Figure 18 show that the release rate has improved compared to the absence of $\mathrm{TiO} 2$ and irradiation and that fuel a value of $38 \%$ after 40 minutes of filtration. This can be explained by an adsorption of $\mathrm{BM}$ on $\mathrm{TiO} 2$. 


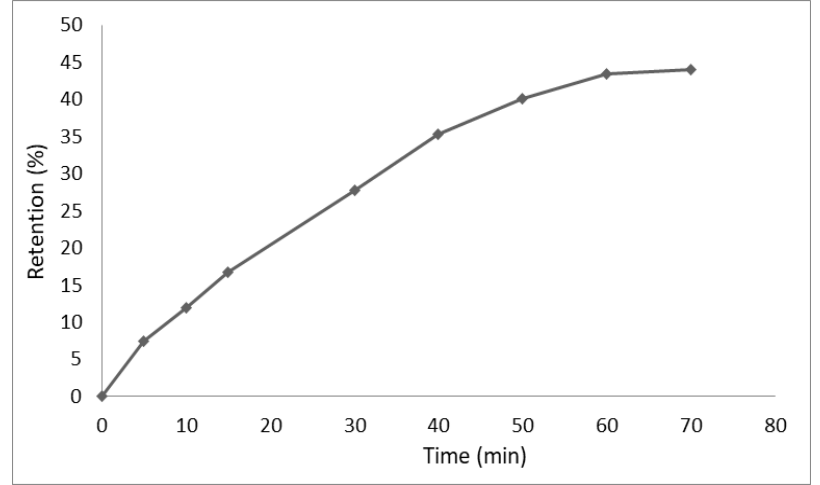

Fig. 18. Filtration of $\mathrm{BM}$ in the presence of $\mathrm{TiO} 2$ and without irradiation on $\mathrm{ZrO} 2 /$ Clay.

\subsection{Study of photodegradation microfiltration membrane separation}

and

The rejection rate of the ceramic membrane for the $\mathrm{TiO} 2$ photocatalyst with two membranes was shown in Figure 19.

In the initial period of the microfiltration, the rejection rate for $\mathrm{TiO}_{2}$ particles was more than $98 \%$. After $40 \mathrm{~min}$, the rejection rate completely $\mathrm{TiO}_{2}$ particles was more than 99.5\%. Meanwhile, no $\mathrm{TiO}_{2}$ particles could be detected in the permeation liquid. This showed that $\mathrm{TiO}_{2}$ photocatalyst was separated completely.

In order to measure the photocatalyst degradation rate in the coupling reactor, the photocatalytic oxidation of methylene blue was conducted in the coupling reactor. The result is shown in Figure 20. The degradation reaches $75 \%$ in 1 hours of filtration.

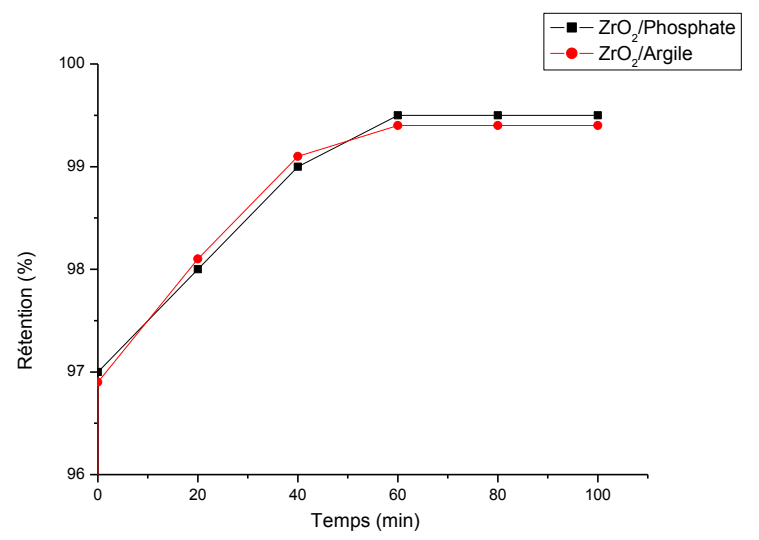

Fig. 19. The rejection rate of $\mathrm{TiO} 2$.

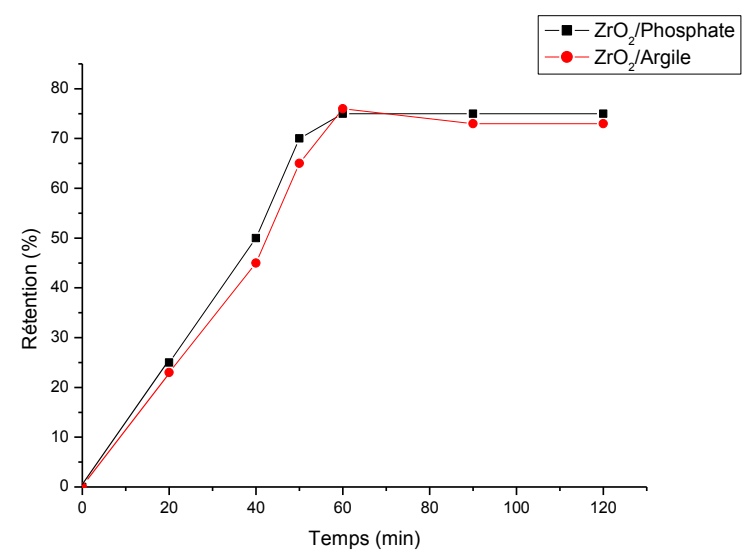

Fig. 20. The rejection rate methylene blue solution

\section{Conclusion}

The preparation and characterization of a new microfiltration membrane based on Moroccan clay has been described and used in this work.

Different tests were studied to confirm the efficiency of the direct coupling of photodegradation and filtration and determine the rate of release of $\mathrm{TiO}_{2}$ particles through the microfiltration membrane.

The photocatalysis membrane separation coupling reactor system was studied. The rejection rate of $\mathrm{TiO}_{2}$ particles, the microfiltration flux and the photocatalytic degradation rate of methylene blue was investigated in the reactor under optimized operating conditions. This coupling reactor can meet the needs of both the separation of the particles and the photocatalytic reaction, and it is suitable for continuous and pilot scale operations.

\section{References}

1. N. El Baraka, N. Saffaj, R. Mamouni, A. Laknifli, S. Alami Younssi, A. Albizane, M. El Haddad, Elaboration of a new flat membrane support from Moroccan clay. Desalin. Water Treat. 52, (2014) 1357-1361.

2. A.Ait Taleb, N. El Baraka, N. Saffaj, A. Laknifli, R. Mamouni, A. Fatni, A.El Hammadi, N. El Qacimi, 2018. New Tubular Ceramic Membranes from Natural Moroccan Clay for Microfiltration. E3S Web of Conferences 37, 01011.

3. N. Saffaj, N. El Baraka, R. Mamouni, H. Zgou, A. Laknifli, S. Alami Younssi, Y. Darman, M. Aboulkacem, O. Mokhtari. New BioCeramic Support Membrane from Animal Bone. j. Micribiol. Biotech. Res, 3 (2013) 1-6.

4. I. Barrouk, S.A. Younssi, A. Kabbabi, M. Persin, A. Albizane, S. Tahiri, Desal. Water Treat. 55 (2015) 53.

5. T. Van Gerven, G. Mul, J.Moulijn, A.Stankiewicz, Chem.Eng.Process46 (2007) 781-789. 
6. S. Mozia, Photocatalytic membrane reactors (PMRs) in water and wastewater treatment. Separation and Purification Technology 73 (2010) 71-91.

7. F. Martinez, M.J. Lopez-Munoz, J. Aguado, J.A. Melero, J. Arsuaga, A. Sotto, R. Molina, Y. Segura, M.I. Pariente, A. Revilla, L. Cerro, G. Carenas, Coupling membrane separation and photocatalytic oxidation processes for the degradation of pharmaceutical pollutants 47 (2013) 5647-5658.

8. D. Ghosh, K.G. Bhattacharyya. Adsorption of methylene blue on kaolinite. Appl. Clay Sci., (2002)20, 295- 300.

9. T. Robinson, G. McMullan, R. Marchant et P.Nigam. Remediation of dyes in textile effluent: a critical review on current treatment technologies with a proposed alternative. Bioresour. Technol., (2001) 77, 247-255.

10. N. Saffaj, R. Mamouni, A. Laknifli, A. Mouna, S. Alami Younssi, A. Albizane 2010, 11 (2), pp. 243 254

11. S. akur, S. Pandey, and O. A. Arotiba, "Development of a sodium alginate-based organic/inorganic superabsorbent composite hydrogel for adsorption of methylene blue," Carbohydrate Polymers, vol. 153, pp. 34-46, 2016.

12. S. Aslam, J. Zeng, F. Subhan et al., "In situ one-step synthesis of Fe3O4@MIL-100 (Fe) core-shells for adsorption of methylene blue from water," Journal of Colloid and Interface Science, vol. 505, pp. 186195, 2017.

13. Bennani Karim et al./ Revue des Sciences de l'Eau 23(4) (2010) 375-388

14. R. Molinari, F. Pirillo, M. Falco, V. Loddo, L. Palmisano: Photocatalytic degradation of dyes by using a membrane reactor, Chemical Engineering and Processing, 2004, 43, 1103-1114.

15. P.R. Gogate, A.B. Pandit, Adv. Environ. Res. 8 (2004) 501-551.

16. J.-M. Herrmann, Catal. Today 53 (1999) 115-129.

17. S. Rehman, R. Ullah, A.M. Butt, N.D. Gohar, J. Hazard. Mater. 170 (2009) 560-569.

18. M.I. Litter, Appl. Catal., B 23 (1999) 89-114.

19. A. Fujishima, X. Zhang, C. R. Chimie 9 (2006) 750-760.

20. A. Fujishima, T.N. Rao, D.A. Tryk, J. Photochem. Photobiol., C 1 (2000) 1-21. 